Check for updates

Cite this: RSC Adv., 2018, 8, 22552

\title{
Accessing new 2D semiconductors with optical band gap: synthesis of iron-intercalated titanium diselenide thin films via LPCVD $\uparrow$
}

\author{
Clara Sanchez-Perez, (DD ab Caroline E. Knapp, ${ }^{a}$ Ross H. Colman, (D) Carlos Sotelo- \\ Vazquez, ${ }^{a}$ Raija Oilunkaniemi, (iD ${ }^{b}$ Risto S. Laitinen (D) *b and Claire J. Carmalt (DD *a
}

\begin{abstract}
Fe-doped $\mathrm{TiSe}_{2}$ thin-films were synthesized via low pressure chemical vapor deposition (LPCVD) of a single source precursor: $\left[\mathrm{Fe}\left(\eta^{5}-\mathrm{C}_{5} \mathrm{H}_{4} \mathrm{Se}\right)_{2} \mathrm{Ti}\left(\eta^{5}-\mathrm{C}_{5} \mathrm{H}_{5}\right)_{2}\right]_{2}$ (1). Samples were heated at $1000^{\circ} \mathrm{C}$ for $1-18 \mathrm{~h}$ and cooled to room temperature following two different protocols, which promoted the formation of different phases. The resulting films were analyzed by grazing incidence X-ray diffraction (GIXRD), X-ray photoelectron spectroscopy (XPS), scanning electron microscope (SEM) and UV/vis spectroscopy. An investigation of the Fe doping limit from a parallel pyrolysis study of $\mathrm{Fe}_{x} \mathrm{TiSe}_{2}$ powders produced in situ during LPCVD depositions has shown an increase in the $\mathrm{Fe}-\mathrm{TiSe}_{2}-\mathrm{Fe}$ layer width with $\mathrm{Fe}$ at\% increase. Powders were analyzed using powder X-ray diffraction (PXRD) involving Rietveld refinement and XPS. UV/vis measurements of the semiconducting thin films show a shift in band gap with iron doping from $0.1 \mathrm{eV}$

( $\left.\mathrm{TiSe}_{2}\right)$ to $1.46 \mathrm{eV}\left(\mathrm{Fe}_{0.46} \mathrm{TiSe}_{2}\right)$.
\end{abstract}

Received 13th April 2018

Accepted 12th June 2018

DOI: $10.1039 / \mathrm{c} 8 \mathrm{ra03174f}$

rsc.li/rsc-advances

\section{Introduction}

The continuous search for high-speed/low-power electronics beyond the current silicon-based devices has incentivised the research on these layered materials with band gaps, redirecting interest from graphene to 2D group 4 and 6 TMDs materials and heterostructures with tuneable band alignments for a variety of nanoelectronic/optoelectronic applications. ${ }^{1-5}$ The design of high-efficiency materials which can convert solar to electrical energy is a continuously increasing research topic, in which the main path nowadays involves thin-film technology. ${ }^{6}$ Early transition metal chalcogenides have been reported to have applications as cathode materials for rechargeable batteries. ${ }^{7}$ Many of them are semiconductors with band gaps lying within the UV-visible region, and are predicted to be strong absorbers of light, which makes them interesting candidates in the search of next generation solar cell energy devices. ${ }^{8}$

Group 4 transition metal diselenides (TMDs) crystallize in the $1 \mathrm{~T}-\mathrm{CdI}_{2}$ structure $P \overline{3} m 1$, with a hexagonal layer of transition metal sandwiched between two hexagonal layers of chalcogen atoms (S, Se, Te). In the crystal structure, layers stack along the $c$

${ }^{a}$ University College London, Department of Chemistry, 20 Gordon St, London, WC1H oAJ, UK. E-mail: c.j.carmalt@ucl.ac.uk

${ }^{b}$ Laboratory of Inorganic Chemistry, Environmental and Chemical Engineering, University of Oulu, P. O. Box 3000, FI-90014 Oulu, Finland. E-mail: risto.laitinen@ oulu.fi

${ }^{c}$ Charles University, Faculty of Mathematics and Physics, Department of Condensed Matter Physics, Ke Karlovu 3, Prague 2, Czech Republic

$\dagger$ Electronic supplementary information (ESI) available. See DOI: 10.1039/c8ra03174f axis via van der Waals forces. ${ }^{9}$ Many kinds of atoms and organic molecules can be intercalated into the van der Waals gap sites of layered TMDs, causing dramatic changes in physical properties of the host materials ${ }^{\mathbf{1 0 , 1 1}}$ and generating a wide variety of magnetic orderings in these so-called intercalated transition metal dichalcogenides (ITMDs). ${ }^{10}$ Owing to their ability to exist in more than one oxidation state, investigation of transition metals and their role in electronic and transport properties of the aforementioned complexes is of great interest. ${ }^{\mathbf{1 2}}$ Ternary chalcogenides of the series $\mathrm{Fe}_{x} \mathrm{TiSe}_{2}$ have a defect NiAs-type lattice. ${ }^{13,14}$ The anions are arranged in hexagonal closed-pack layers sandwiching octahedrally coordinated $\mathrm{Ti}^{4+}$ cations. Previous studies of the $\mathrm{Fe}_{x} \mathrm{TiSe}_{2}$ system as a function of $x$ showed the existence of several phases corresponding to superstructures of the $\mathrm{TiSe}_{2}$ reference cell, as a result of an ordering of iron and vacancies in the van der Waals gap for values of $x>0.2 .^{13,15}$ It was found that hybridization of Ti $3 \mathrm{~d}$ and Fe $3 d$ states, along with the overlap of titanium and iron $d_{z^{2}}$ electron shells along the $c$ axis leads to covalent bonding between layers; therefore a lattice compression occurs along the $c$ axis, although the unit cell volume increases linearly with iron concentration. ${ }^{16-18}$

The $\mathrm{Fe}_{x} \mathrm{TiSe}_{2}$ system presents retrograde solubility in the solid state; an increase in the temperature of the system results in iron release, and on further heating it re-enters the lattice. This phenomenon is caused by the thermal expansion of the impurity band of the $\mathrm{Fe} 3 \mathrm{~d} / \mathrm{Ti} 3 \mathrm{~d}$ hybrid states. Thermally induced phase transitions are of first order, and therefore the specimen state at the given temperature can be fixed by quenching. ${ }^{18}$ 
Bulk $\mathrm{TiSe}_{2}$ shows metallic conductivity and an optical band gap of $0.1 \mathrm{eV} .{ }^{19}$ Upon intercalation of high spin $\mathrm{Fe}^{2+}$ in the $\mathrm{TiSe}_{2}$ "host" structure, the electrons donated from iron contribute to the titanium $t_{2 g}$ band suppressing its charge density wave behaviour $^{20}$ and increasing the resistivity of the material with increasing iron concentration. ${ }^{11} \mathrm{~A}$ transition from spin glass behaviour to an antiferromagnetic regime occurs at percolation threshold of intercalated iron $x>0.2$ due to coupling between the iron magnetic moments and superexchange interactions..$^{13,17}$

Conventional methods for preparation of binary and ternary transition metal dichalcogenides involve heating of high purity elements at high temperatures for long periods of time, and requires several homogenizing steps, making their synthesis long and expensive. ${ }^{16,18,21}$ The decomposition of metal chalcogenolato complexes to metal chalcogenides takes place at significantly lower temperatures, and they provide high purity materials required for electronic applications. Recent research has highlighted the importance of careful precursor design, in order to facilitate cleaner decomposition, ${ }^{22}$ lowering contamination and improving performance of the resultant functional material. Chemical vapour deposition (CVD) has drawn attention as a method to synthesis thin films of functional materials, ${ }^{23}$ including metal selenides. ${ }^{24,25}$ The use of single source precursors in CVD has a number of advantages, not least the simplification of the decomposition mechanism since all required elements are delivered to the desired substrate at the same time. Earlier this year compounds of the type: $\left[\mathrm{Fe}\left(\eta^{5}-\right.\right.$ $\left.\left.\mathrm{C}_{5} \mathrm{H}_{4} \mathrm{Se}\right)_{2} \mathrm{M}\left(\eta^{5}-\mathrm{C}_{5} \mathrm{H}_{5}\right)_{2}\right]_{2}[\mathrm{M}=\mathrm{Ti}(\mathbf{1}), \mathrm{Zr}(2), \mathrm{Hf}(3)]$ have been reported $^{22}$ for potential utilization as single source precursors. In particular, the use of the titanium species $\mathbf{1}$ in the LPCVD fabrication of iron intercalated titanium diselenide $\mathrm{Fe}_{x} \mathrm{TiSe}_{2}$ could remove any pre-reaction issues or formation of unwanted side products and facilitates a facile, one step route to functional semiconductor materials with tuneable band gap.

There are only a handful of reports using CVD to produce thin films of metal chalcogenides. ${ }^{19,26-29}$ The work presented herein explores the capability of our precursors to generate high quality thin films of iron-doped titanium selenide, with the objective to achieve desired optical and electrical properties. Following the synthesis of the single source precursor, $\left[\mathrm{Fe}\left(\eta^{5}\right.\right.$ $\left.\left.\mathrm{C}_{5} \mathrm{H}_{4} \mathrm{Se}\right)_{2} \mathrm{Ti}\left(\eta^{5}-\mathrm{C}_{5} \mathrm{H}_{5}\right)_{2}\right]$ (1), LPCVD has been used to produce functional thin films of $\mathrm{Fe}_{x} \mathrm{TiSe}_{2}$. Here, we report for the first time, to the best of our knowledge, the simultaneous synthesis of polycrystalline powder $\mathrm{Fe}_{0.46} \mathrm{TiSe}_{2}$ and its thin film deposition. This approach could offer a faster alternative to the conventional synthetic route of iron-intercalated titanium diselenides, involving only a one-step heat treatment.

\section{Experimental section}

\section{Precursor synthesis}

The precursors were synthesized according to literature. ${ }^{22}$ $N, N, N^{\prime}, N^{\prime}$-Tetramethylethylenediamine (Aldrich) was distilled over sodium and stored over sieves $3 \AA(20 \% \mathrm{~m} / \mathrm{v})$ for $24 \mathrm{~h}$ and ferrocene (Merck, 99\%) was freeze dried for $12 \mathrm{~h}$ prior to use. Selenium (shot, Aldrich), nBuLi (2.5 M in Hexane, Aldrich),
${ }^{t}$ BuLi (1.7 M in Hexane, Aldrich) and bis(cyclopentadienyl)titanium(Iv)dichloride (Aldrich) were used as purchased. Dry THF (99.9\% in Argon, Sigma) and dry toluene were stored over a sodium mirror for $24 \mathrm{~h}$ prior to use, and pre-dried dichloromethane was dried over Mo sieves $3 \AA(20 \% \mathrm{~m} / \mathrm{v})$ for $48 \mathrm{~h}$ prior to use. All preparations were undertaken using Schlenk line techniques, and all glassware was dried for $12 \mathrm{~h}$ at $200^{\circ} \mathrm{C}$ prior to use. Synthesis of the precursor was performed under argon, which was passed over a drying column. After isolation, the polycrystalline powder precursor was stored in a glovebox under an Argon atmosphere. Synthesis and purification of the precursor was confirmed by NMR:22 ${ }^{1} \mathrm{H}$ NMR $(600 \mathrm{MHz}) \delta / \mathrm{ppm}$ $\left(\mathrm{C}_{6} \mathrm{D}_{6}\right): 5.67$ (s, 10H); $4.35(\mathrm{~m}, 8 \mathrm{H}) .{ }^{13} \mathrm{C}\left\{{ }^{1} \mathrm{H}\right\}$ NMR $(600 \mathrm{MHz}) \delta /$ ppm $\left(\mathrm{C}_{6} \mathrm{D}_{6}\right): 110.99(\mathrm{~m}, \mathrm{Fc}) ; 111.26(\mathrm{~m}, \mathrm{Cp})$.

\section{Deposition studies - apparatus and characterization}

LPCVD experiments were carried out in a quartz tube under dynamic vacuum $\left(10^{-1}\right.$ torr) embedded inside a furnace to allow uniform heating. The temperature was controlled using Pt-Rh thermocouples. The polycrystalline precursor was spread evenly in a glazed ceramic boat $\left(0.9 \times 1.4 \times 10.3 \mathrm{~cm}\right.$, VWR ${ }^{\circledR}$ Cat. no. 459-0224) and heated up to $1000{ }^{\circ} \mathrm{C}$ for $1-18 \mathrm{~h}$ in order to achieve its sublimation and the formation of the final product. Powders were collected alongside films on quartz slides $(2.5 \mathrm{~cm}$ $\times 1.0 \mathrm{~cm} \times 2 \mathrm{~mm}$ ) supplied by Multi-Lab, which were cleaned using acetone (99\%), isopropanol (99\%), and distilled water and dried at $200{ }^{\circ} \mathrm{C}$ overnight prior to use. The precursor ( $c a .0 .15 \mathrm{~g}$ ) sublimed and deposited over the slides in the hot zone of the reactor. After several attempts two cooling protocols were established: 1 - cooled at $13^{\circ} \mathrm{min}^{-1}$ to $450{ }^{\circ} \mathrm{C}$ and then quenched; 2 - gradual cooling of $13^{\circ} \mathrm{min}^{-1}$ to $355^{\circ} \mathrm{C}$, followed by $2{ }^{\circ} \mathrm{C} \mathrm{min}^{-1}$ to room temperature. The tube was then transported inside the glovebox, where the remaining powder and the quartz slides were stored for characterization. The powder samples were grinded in a metal mortar inside the glovebox, loaded to $3 \mathrm{~mm}$ borosilicate capillaries and sealed for characterization.

PXRD data were collected on a STOE diffractometer using monochromated Mo $K_{\alpha 1}$ radiation $(0.70903 \AA$; $50 \mathrm{kV}, 30 \mathrm{~mA})$ and 4 scans per measurement over the range $2 \theta$ of $10-40^{\circ}$, with a step size of $0.5^{\circ}$ and a count time of $10 \mathrm{~s}$ per step. GIXRD analysis was performed using a Bruker-Axs D8 (Lynxeye XE) diffractometer with monochromated $\mathrm{Cu} \mathrm{K}_{\alpha 1}$ radiation (1.54184 $\AA ; 20 \mathrm{kV}, 5 \mathrm{~mA})$. The films were analyzed with a grazing incident angle $(\theta)$ of $1^{\circ}$. Thin film XRD studies showed high fluorescence due to use of copper radiation and the presence of iron (Fig. S1 $\dagger$ ). Polycrystalline powders from the same experiments were therefore loaded into capillaries and analyzed using a STOE Stadi P diffractometer (Mo K $\alpha_{\alpha 1}$ radiation, $0.70903 \AA$, 50 $\mathrm{kV}, 30 \mathrm{~mA}$ ), in which less fluorescence was detected. For the thin films X-ray photoelectron spectroscopy (XPS) was performed using a Thermo $\mathrm{K}$ alpha spectrometer with monochromated $\mathrm{Al} \mathrm{K} \alpha$ radiation (8.3418 $⿱$ ) $)$, a dual beam charge compensation system and a constant pass energy of $50 \mathrm{eV}$. Survey scans were collected in the range of $0-1200 \mathrm{eV}$. High resolution peaks were used for the principal peaks of $\mathrm{Ti}(2 \mathrm{p}), \mathrm{Fe}$ 
(2p), Se (3d), and C (1s). The peaks were modelled using sensitivity factors to calculate the film composition. The area underneath these bands was an indicator of the element concentration within the region of analysis (spot size $400 \mu \mathrm{m}$ ). Scanning electron microscope (SEM) studies were carried out using a JEOL $6301(10 \mathrm{kV})$ and a JEOL JSM-6700F field emission instruments, after sputtering of the samples with a thin layer of gold for increased imaging. UV-vis spectroscopy was performed using a Shimadzu UV-2600 240 V IVDD UV/vis Spectrophotometer in the 350-900 $\mathrm{nm}$ range. A Labsphere reflectance standard was used as reference in the UV-vis measurements.

\section{Results and discussion}

$\left[\mathrm{Fe}\left(\eta^{5}-\mathrm{C}_{5} \mathrm{H}_{4} \mathrm{Se}\right)_{2} \mathrm{Ti}\left(\eta^{5}-\mathrm{C}_{5} \mathrm{H}_{5}\right)_{2}\right]_{2}(\mathbf{1})$ was selected as a single source precursor, since the Fe doping is expected to tune the optical and electrical band gap of $\mathrm{TiSe}_{2}$. The $\mathrm{Fe}: \mathrm{Ti}: \mathrm{Se}$ ratio in $\mathbf{1}$ is $1: 1: 2$, which facilitates an excess of iron dopant and therefore the maximum amount of intercalation into the targeted $\mathrm{TiSe}_{2}$ lattice. Following the synthesis and characterisation of $\mathbf{1},{ }^{22}$ LPCVD studies produced thin films which were uniform, adherent and showed a good coverage of the substrate. For each experiment powder deposits were also collected and analysed using PXRD to calculate the composition using the Rietveld refinement (Scheme 1). These depositions on quartz substrates were conducted alongside ceramic boats containing $\mathbf{1}$ at $1000{ }^{\circ} \mathrm{C}$, by varying the reaction time between one and eighteen hours. It was established that two different cooling processes were required in order to prove the retrograde solubility particular to the $\mathrm{Fe} / \mathrm{Fe}_{x} \mathrm{TiSe}_{2}$ system, and find the best conditions for maximum amount of intercalated iron in the structure. In the first process the reactor was cooled to $13^{\circ} \mathrm{min}^{-1}$ until $450{ }^{\circ} \mathrm{C}$ and the quartz tube was subsequently quenched with water; in the second process a gradual cooling of the reactor was carried out at $13^{\circ} \mathrm{min}^{-1}$ until reaching $355{ }^{\circ} \mathrm{C}$, followed by a slower cooling process of $2^{\circ} \mathrm{min}^{-1}$ until it reached room temperature. Subsequently, air and moisture sensitive black powder samples with a metallic shine, as well as black thin films on quartz (also exhibiting a metallic lustre) were handled under an inert environment for analysis.

This custom experimental setup of running the LPCVD and pyrolyzing the powder concurrently facilitated analysis, allowing higher quality XRD data to be collected from the powder samples.

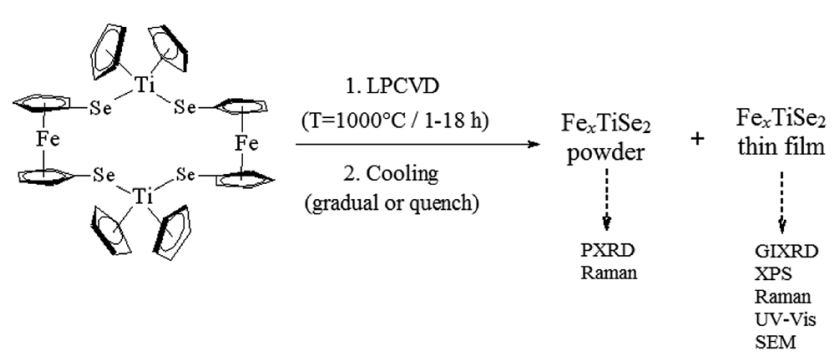

Scheme 1 Scheme of the LPCVD of precursor (1) and analysis techniques for products (powders and films).
The thin films deposited via LPCVD were analysed using GIXRD, however as a result of the $\mathrm{Cu} \mathrm{K} \mathrm{K}_{\alpha 1}$ radiation used, fluorescence effects due to the content of iron in the films made characterisation unreliable (Fig. S1 $\dagger$ ). Polycrystalline powders of LPCVD products were examined by PXRD using Mo $\mathrm{K}_{\alpha 1}$ source in order to reduce the fluorescence effects in the patterns. The PXRD patterns of the powder samples produced confirmed the formation of the intercalation compounds $\mathrm{Fe}_{x} \mathrm{TiSe}_{2}$ (Fig. 1). Structural refinement using Rietveld analysis of the data confirmed the maximum intercalation of iron where $x=0.48(2)$ (Table 1), which structure is shown in Fig. 2.

As can be seen in the PXRD data (Fig. 1), the two cooling protocols lead to distinctly different products subsequent to identical pyrolysis. The observation of substantial elemental and oxidised iron in the quenched sample suggests a lower level of intercalation within the $\mathrm{TiSe}_{2}$ structure, whilst the slow-cool protocol leads to a significantly reduced level of un-intercalated Fe. A distortion from the hexagonal $P \overline{3} m 1$ space-group of the parent $\mathrm{TiSe}_{2}$ compound has previously been observed upon intercalation of Fe at levels greater than $x=0.2 \cdot{ }^{16}$ At a value of $x$ $=0.25$ and $x=0.5$, superstructures are observed due Fe and vacancy ordering as well as a monoclinic distortion. ${ }^{15}$

Whilst the $\mathrm{Fe}_{x} \mathrm{TiSe}_{2}$ phase seen in the quench-cooled material is best described using the parent hexagonal $P \overline{3} m 1$ spacegroup, the fit of the slow-cooled $\mathrm{Fe}_{x} \mathrm{TiSe}_{2}$ structure is significantly improved when using the distorted $I 2 / \mathrm{m}$ space-group. Intercalation of $\mathrm{Fe}$ between layers results in a covalent $\mathrm{Fe}-\mathrm{Ti}-$ Fe bond and has been shown to decrease the inter-layer spacing and subsequently the $c$ lattice parameter. Ignoring the small monoclinic distortion $\left(\beta=89.69(2)^{\circ}\right)$ the $I 2 / m$ structure is related to the parent $P \overline{3} m 1$ structure through the conversion $a=$ $a^{\prime} \sqrt{ } 3, b=a^{\prime}, c=2 c^{\prime}$. An increase in the total layer width, Fe-

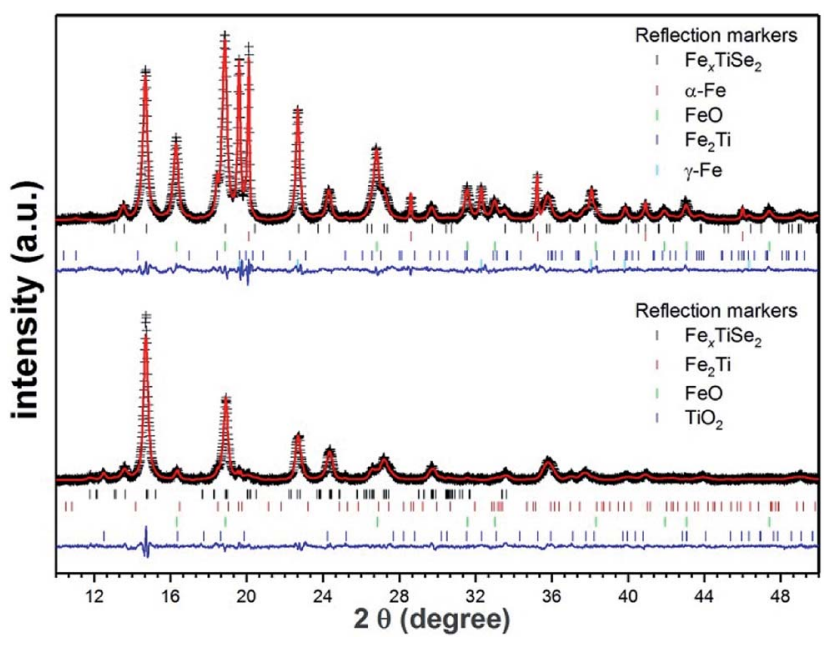

Fig. 1 Rietveld refinement plots of the diffraction data collected from pyrolysis of 1 for $18 \mathrm{~h}$ followed by quenching (top) and gradual cooling (bottom). The crosses represent experimental diffraction pattern, the red line is the calculated pattern, and the blue line represents the difference $y_{\text {obs }}-y_{\text {calc }}$. The calculated Bragg angles $(2 \theta)$ are marked by the vertical bars. Structural analysis was performed using the GSAS package. ${ }^{30}$ For clarity, the displayed data are background-subtracted to remove the large contribution from Fe fluorescence. 
Table 1 Refined parameters and fit indicators for the Rietveld refinement of diffraction data for pyrolysis of 1 for the two different cooling protocols

\begin{tabular}{|c|c|c|}
\hline Cooling protocol & Gradual & Quenched \\
\hline $\mathrm{Fe}_{x} \mathrm{TiSe}_{2}$ space-group & $I 2 / m$ & $P \overline{3} m 1$ \\
\hline Se-Ti-Se sandwich thickness $(\AA)$ & $3.126(7)$ & $3.009(12)$ \\
\hline $\mathrm{Fe}_{x} \mathrm{TiSe}_{2}$ phase fraction (wt $\left.\%\right)$ & $82.4(8)$ & $29.75(12)$ \\
\hline Impurity phases and fractions (wt $\%$ ) & $\mathrm{Fe}_{2} \mathrm{Ti}=1.35(8), \mathrm{FeO}=6.6(3), \mathrm{TiO}_{2}=9.7(4)$ & $\begin{array}{l}\alpha-\mathrm{Fe}=6.9(4), \gamma-\mathrm{Fe}=17.3(6), \mathrm{FeO}=35.2(9) \\
\mathrm{Fe}_{2} \mathrm{Ti}=10.8(2)\end{array}$ \\
\hline
\end{tabular}

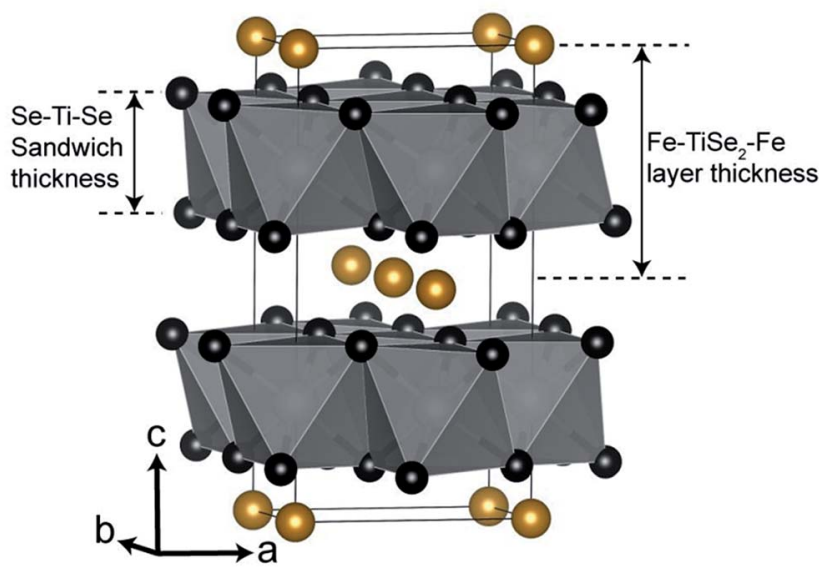

Fig. 2 Structural diagram of $\mathrm{Fe}_{0.48} \mathrm{TiSe}_{2}$. Titanium atoms in white (inside octahedra), selenium atoms in black and iron atoms in gold. ${ }^{41}$

$\mathrm{TiSe}_{2}-\mathrm{Fe}$ (the Se-Ti-Se sandwich thickness plus the Fecontaining van-der-Waals gap Se-Fe-Se), when comparing the quench cooled protocol $(c=5.9932(6) \AA)$ and the slow cooled $(c)$ $2=5.9629(7) \AA)$ are in line with those seen in previous studies and confirm the reduced Fe content. Shkvarina et al. also found that whilst the total layer $\left(\mathrm{Fe}-\mathrm{TiSe}_{2}-\mathrm{Fe}\right)$ width decreases on $\mathrm{Fe}-$ doping, an increase in the Se-Ti-Se sandwich thickness is observed due to weakening of the Ti-Se bonding. ${ }^{18}$ We do observe a slight increase in Se-Ti-Se thickness in refinements of the slow-cooled, higher Fe-doped, material (3.126(7) vs. $3.009(12) \AA$ ) but the values are almost within error and higher quality data would be needed to confirm this feature.

The observed space-group symmetry, the refined Fe content and the inter-layer lattice parameter all confirm the increased intercalated-Fe content upon gradual cooling of the sample, compared to quench-cooling from $450{ }^{\circ} \mathrm{C}$. This is further evidenced by the observation of large fractions of both elemental and oxidised Fe as impurities in the quench cooled sample. These observations are concordant with those reported for materials such as $\mathrm{Fe}_{x} \mathrm{TiSe}_{2}$ showing retrograde Fe solubility on heating. ${ }^{18}$ At temperatures $>1000{ }^{\circ} \mathrm{C}$ a large $x$ value is obtainable within the lattice but on cooling Fe becomes less soluble being seen instead as a mixed phases of $\mathrm{Fe}$ and $\mathrm{Fe}_{x} \mathrm{TiSe}_{2}$. At lower temperatures, solubility again increases and greater values of $x$ are achievable. ${ }^{18}$ During precursor decomposition and $\mathrm{Fe}_{x} \mathrm{TiSe}_{2}$ deposition, a high intercalation level is expected. On cooling the film, Fe solubility changes and a mixture of discrete $\mathrm{Fe}$ and $\mathrm{Fe}_{x} \mathrm{TiSe}_{2}$ phases should then be observed. Quench-cooling from this mixed-phase regime is expected to lead to the observation of a significant elemental Fe content and a reduced level of intercalation, in line with our results. Gradual cooling, however, gives the lattice time to allow Fe-reintercalation, increasing $x$, and decreasing the level of observed elemental or subsequently oxidised iron.

XPS was used to study the environment of the gradually cooled $\mathrm{Fe}_{0.48} \mathrm{TiSe}_{2}$ powder sample and thin films. As XPS is a surface-sensitive technique $(\leq 10 \mathrm{~nm}),{ }^{31}$ several depths within the bulk of the film were investigated by etching the surface with argon sputtering. Previous works have shown that $\mathrm{TiSe}_{2}$ materials present a Ti2p environment at $456.2 \mathrm{eV}$ (ref. 32) whereas for $\mathrm{Fe}_{0.40} \mathrm{TiSe}_{2}$ materials the Ti $2 \mathrm{p}_{3 / 2}$ band appears at $455.2 \mathrm{eV} \cdot{ }^{33} \mathrm{XPS}$ measurements of the powder sample exhibit two titanium environments with $\mathrm{Ti} 2 \mathrm{p}_{3 / 2}=455.4$ and $458.7 \mathrm{eV}$, corresponding to $\mathrm{Ti}^{4+}$ species of respectively $\mathrm{TiSe}_{2}$ (ref. 32) and $\mathrm{TiO}_{2}$, respectively ${ }^{34}$ (Fig. 3a). Additionally two selenium environments were observed, the first: $3 \mathrm{~d}_{5 / 2}=54.2 \mathrm{eV}, 3 \mathrm{~d}_{3 / 2}=$
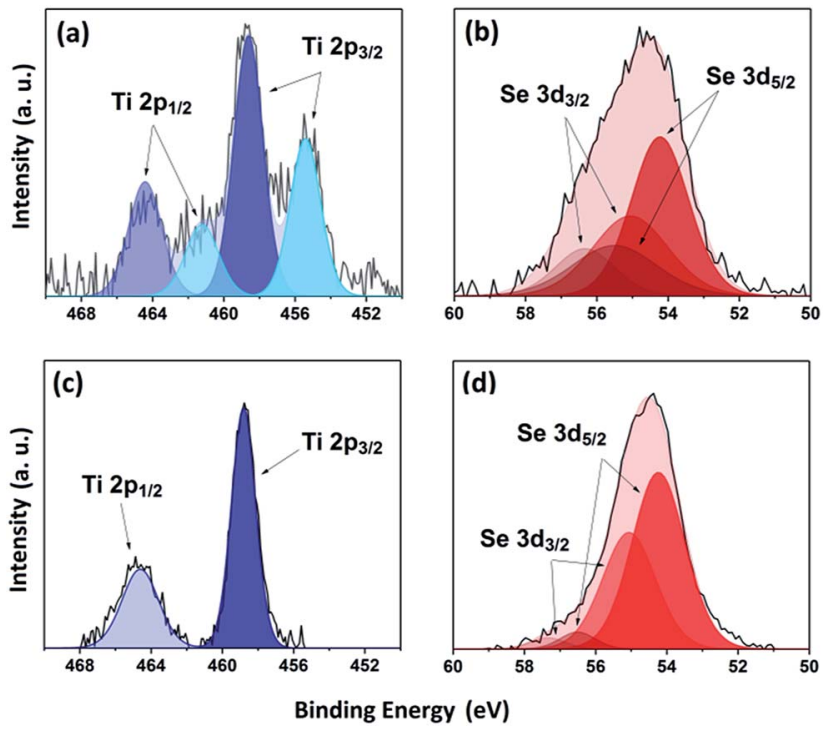

Fig. 3 XPS transitions for powder (top) and film surface (bottom) of Ti $2 \mathrm{p}\left(\mathrm{a}\right.$ and $\mathrm{c}$ ) and Se $3 \mathrm{~d}\left(\mathrm{~b}\right.$ and d) environments of $\mathrm{Fe}_{0.48} \mathrm{TiSe}_{2}$. 
$55.0 \mathrm{eV}$ corresponds to that of $\mathrm{TiSe}_{2}\left(\mathrm{Se} 3 \mathrm{~d}_{5 / 2}=54.1 \mathrm{eV}\right)^{32}$ while the second: $3 \mathrm{~d}_{5 / 2}=55.4 \mathrm{eV}, 3 \mathrm{~d}_{3 / 2}=56.3 \mathrm{eV}$ coincides with $\mathrm{Se}^{0}$ (Fig. 3b), likely due to decomposition of the sample during exposure to air prior to measurement. ${ }^{32,35}$

The thin films showed a single environment with components at $\mathrm{Ti} 2 \mathrm{p}_{3 / 2}=458.7 \mathrm{eV}$ and $\mathrm{Ti} 2 \mathrm{p}_{1 / 2}=464.6 \mathrm{eV}$ at the surface, demonstrating the formation of superficial $\mathrm{TiO}_{2}$ (ref. 34) due to the exposure of the film to air prior to its measurement (Fig. 3c). It should be noted that the process of sputtering under argon while etching reduces the $\mathrm{Ti}^{4+}$ species to $\mathrm{Ti}^{3+}$ and cannot be easily fitted. For the $\mathrm{Fe}_{0.48} \mathrm{TiSe}_{2}$ thin film, two components of a major environment Se $3 d_{5 / 2}$ and $3 d_{3 / 2}$ were observed at 54.2 and $55.1 \mathrm{eV}$ (Fig. 3d), consistent with the existence of $\mathrm{Se}^{2-}$ species of $\mathrm{TiSe}_{2} \cdot{ }^{32}$ It is worth noting that a minor second environment in the thin film was observed for Se at $56.5 \mathrm{eV}\left(3 \mathrm{~d}_{5 / 2}\right)$ and $57.3 \mathrm{eV}\left(3 \mathrm{~d}_{3 / 2}\right)$. It could be attributed to Se-Fe-Se interaction, further evidencing the intercalation of iron (Fig. 3d). ${ }^{35,36}$ XPS profile of selenium remains the same upon etching, therefore no other environments of selenium are detected in the film.

Owing to the well documented multiplet splitting in species of high spin Fe(II), XPS spectra cannot be fitted quantitatively for samples containing $\mathrm{Fe}_{x} \mathrm{TiSe}_{2}{ }^{37}$ Nonetheless, a clear visual change in the Fe XPS of the samples is apparent (as can be evidenced in Fig. S2 $\dagger$ ). It is highly likely that $\mathrm{Fe}_{3} \mathrm{O}_{4}$ is present both in the powder and in the surface of the thin film due to exposure to air. However, these species were not found upon XPS depth profile analysis in the thin film. As a result of the monoclinic structural distortion in $\mathrm{Fe}_{0.48} \mathrm{TiSe}_{2}$, an ordering of iron atoms results in the formation of a sequence of octahedral site chains in the van der Waals gaps. ${ }^{33}$ XPS of inner layers $(300 \mathrm{~s}$ etch) showed a Fe 2p environment at $706.7 \mathrm{eV}$ and $719.2 \mathrm{eV}$ (Fig. S2 $\dagger$ ), which coincides with the band corresponding to the metallic $\mathrm{Fe}-\mathrm{Fe}$ bond in $\mathrm{Fe}_{0.40} \mathrm{TiSe}_{2} \cdot{ }^{33}$ Interestingly, previous works have reported that $\mathrm{FeSe}_{2}$ materials present a Fe $2 \mathrm{p}$
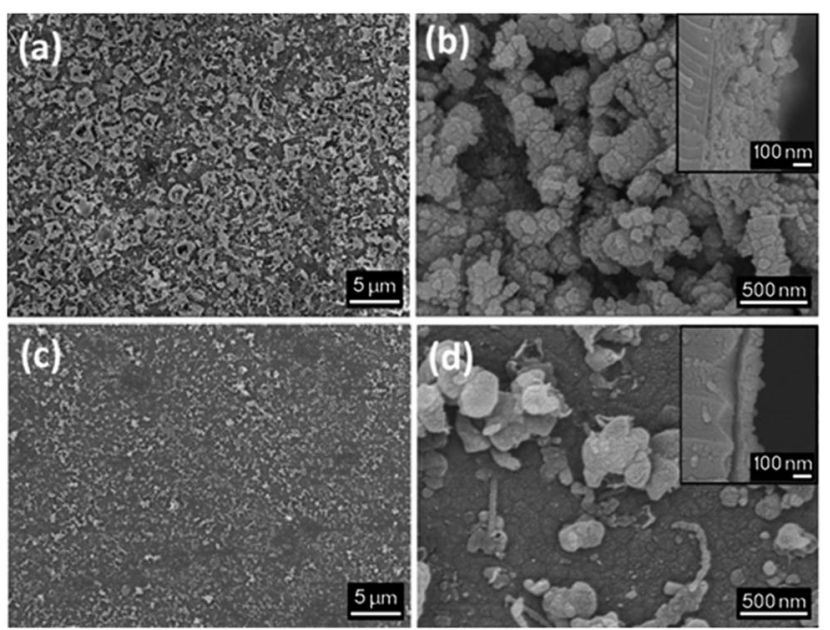

Fig. 4 SEM micrographs of $\mathrm{Fe}_{0.48} \mathrm{TiSe}_{2}$ deposited at $1000^{\circ} \mathrm{C}$ for $1 \mathrm{~h} \mathrm{(a}$ and b) and for $18 \mathrm{~h}$ (c and d). Augmentation for micrographs are $\times 3000$ for (a) and (c), and $\times 40000$ for (b) and (d). Side-on SEM micrographs of each sample are shown in the top right corners.
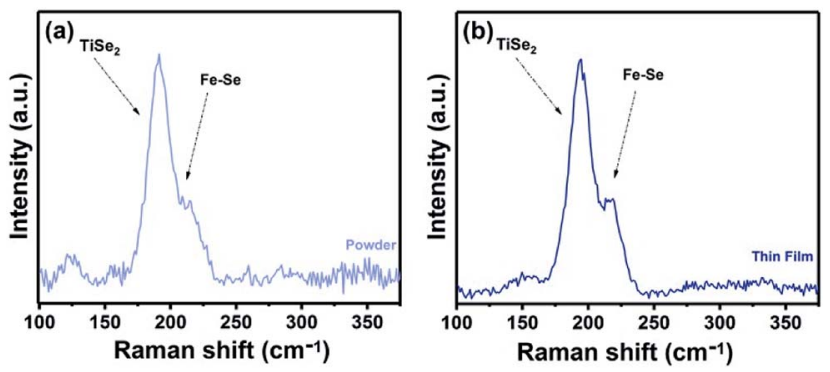

Fig. 5 Raman spectra of (a) powder and (b) thin film sample of $\mathrm{Fe}_{0.48} \mathrm{TiSe}_{2}$ produced at $1000{ }^{\circ} \mathrm{C}$ for $18 \mathrm{~h}$ using the gradual cooling protocol.

environment at $2 \mathrm{p}_{3 / 2}=707.1 \mathrm{eV}$ and $2 \mathrm{p}_{1 / 2}=719.8 \mathrm{eV}$, which would corroborate the presence of $\mathrm{Fe}^{2+}$ species intercalated between layers of selenium. ${ }^{35}$

Carbon contamination was found in the surface, which decreased upon etching (Fig. S3†). Elemental ratios could not be further corroborated by XPS analysis due to the air sensitivity of the samples.

SEM images of the thin films display growth of clusters of crystallites, resulting in a "bubbled" surface (Fig. $4 \mathrm{a}$ and b). The films deposited for $1 \mathrm{~h}$ display an irregular morphology, promoting the absorption of moisture as well as preventing a smooth deposition of a potential coating material. The effect of annealing under a static vacuum for $18 \mathrm{~h}$ leads to a smoother surface and an decrease in film thickness (Fig. 4c and d). A compacting process of the film occurs upon annealing, resulting into a decrease if film thickness. Film thicknesses are $\sim 250 \mathrm{~nm}$ for the film deposited for $1 \mathrm{~h}$ and $\sim 120 \mathrm{~nm}$ for the film deposited for $18 \mathrm{~h}$ (annealed).

Raman spectroscopy was used to study of the powder samples and the $\mathrm{Fe}_{x} \mathrm{TiSe}_{2}$ thin films. Raman spectra of both

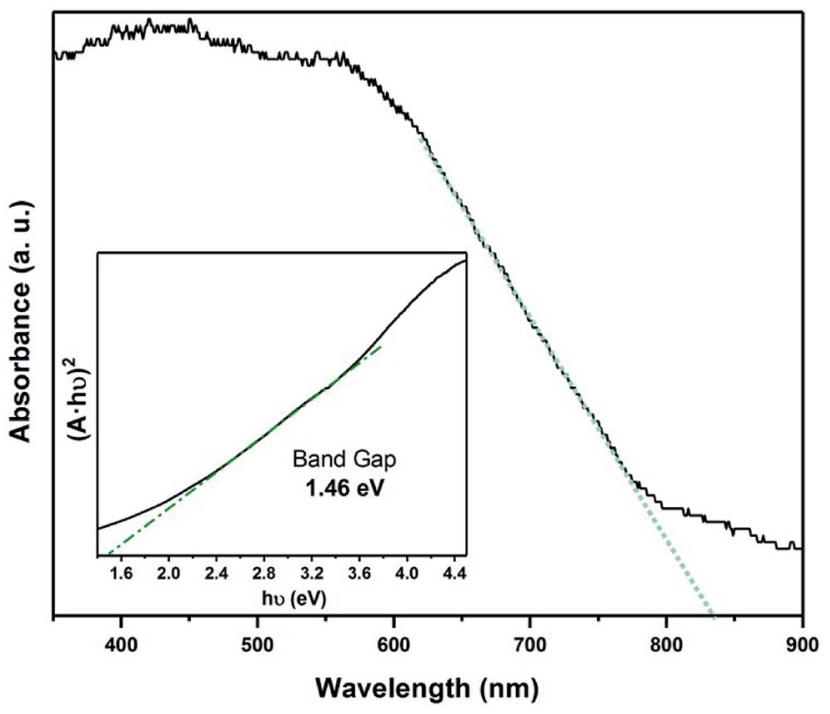

Fig. 6 Optical absorption spectrum of $\mathrm{Fe}_{0.48} \mathrm{TiSe}_{2}$ calculated from transmittance $\left(A=2-\log _{10} T \%\right.$ ) and band gap calculation using a Tauc plot. 
powders and thin film corresponding to the gradual cooling process exhibit a characteristic band at $195 \mathrm{~cm}^{-1}$, very close to the $\mathrm{A}_{1 \mathrm{~g}}$ band of TiSe ${ }_{2}{ }^{38}$ as well as a band at $218 \mathrm{~cm}^{-1}$ in the area expected for a Fe-Se band (Fig. 5)..$^{39}$ The Raman spectroscopic study of the "quenched" film revealed the characteristic strong bands for $\mathrm{Fe}_{3} \mathrm{O}_{4}$, as a result of the rapid oxidation of the excess iron (Fig. S4 $\uparrow$ ). ${ }^{40}$ The optical absorption spectrum $\mathrm{Fe}_{0.48} \mathrm{TiSe}_{2}$ was calculated from transmittance measurements of the films, and it is shown in Fig. 6. The variation of $(\alpha h \nu)^{2}$ versus the $h \nu$ was linear at the absorption edge, which confirmed that $\mathrm{Fe}_{0.48} \mathrm{TiSe}_{2}$ is a semiconductor with a direct band gap of $1.46 \mathrm{eV}$ (Fig. 6). As such these new Fe-doped $\mathrm{TiSe}_{2}$ films are a breakthrough in the development of multifunctional advanced materials with tuneable properties for a wide range of applications.

\section{Conclusions}

Simultaneous synthesis of iron-intercalated $\mathrm{TiSe}_{2}$ powder samples and thin films from the single source precursor 1 were achieved by treatment at $1000{ }^{\circ} \mathrm{C}$ for periods of $1-18 \mathrm{~h}$. The use of two distinct cooling protocols yielded $\mathrm{Fe}_{x} \mathrm{TiSe}_{2}$ materials with different degree of iron intercalation. Maximum intercalation was reported with the formation of $\mathrm{Fe}_{0.48} \mathrm{TiSe}_{2}$, performing a gradual cooling process to room temperature. Raman spectroscopy for this sample confirmed both thin films and powders synthesized in the same experiment to be the same material. Intercalation of iron with a fractional occupancy of $0.48 \pm 2$ in the host structure of layered $\mathrm{TiSe}_{2}$ shows a significant increase in the band gap from $0.1 \mathrm{eV}$ to $1.46 \mathrm{eV}$, which lies close to the limit of maximum solar conversion efficiency (ShockleyQueisser limit) and is consistent with potential application as ptype absorber layer in photovoltaic cells. The development of thin film technology has revolutionized our way to design materials with specific structures and to integrate these architectures into functional devices. For the first time, thin films of iron-doped titanium diselenide have been deposited through a convenient one-step heat process, opening a range of potential applications in the field of optoelectronics and the solar energy industry.

\section{Conflicts of interest}

There are no conflicts to declare.

\section{Acknowledgements}

Dr Steven Firth is thanked for providing useful discussions, as well as access and training to SEM instrument. This work was supported by the Fortum Foundation, UCL and the Ramsay Memorial Trust.

\section{Notes and references}

1 S. Z. Butler, S. M. Hollen, L. Cao, Y. Cui, J. A. Gupta, H. R. Gutiérrez, T. F. Heinz, S. S. Hong, J. Huang, A. F. Ismach, E. Johnston-Halperin, M. Kuno, V. V. Plashnitsa, R. D. Robinson, R. S. Ruoff,
S. Salahuddin, J. Shan, L. Shi, M. G. Spencer, M. Terrones, W. Windl and J. E. Goldberger, ACS Nano, 2013, 7, 28982926.

2 D. Akinwande, N. Petrone and J. Hone, Nat. Commun., 2014, $5,5678$.

3 G. Fiori, F. Bonaccorso, G. Iannaccone, T. Palacios, D. Neumaier, A. Seabaugh, S. K. Banerjee and L. Colombo, Nat. Nanotechnol., 2014, 9, 768-779.

4 J. Gao, X. Di, W. Li, L. Feng, J. Zhang, L. Wu, B. Li, W. Wang, G. Zeng and J. Yang, Thin Solid Films, 2014, 550, 638-642.

5 G. R. Bhimanapati, Z. Lin, V. Meunier, Y. Jung, J. Cha, S. Das, D. Xiao, Y. Son, M. S. Strano, V. R. Cooper, L. Liang, S. G. Louie, E. Ringe, W. Zhou, S. S. Kim, R. R. Naik, B. G. Sumpter, H. Terrones, F. Xia, Y. Wang, J. Zhu, D. Akinwande, N. Alem, J. A. Schuller, R. E. Schaak, M. Terrones and J. A. Robinson, ACS Nano, 2015, 9, 1150911539.

6 C. E. Knapp and C. J. Carmalt, Chem. Soc. Rev., 2016, 45, 1036-1064.

7 Lithium Batteries, ed. J.-P. Gabano, Academic Press, London, New York, 1983.

8 M. Abdulsalam and D. P. Joubert, Phys. Status Solidi B, 2016, 253, 705-711.

9 A. Borghesi, C. Chen-jia, G. Guizzetti, L. Nosenzo, E. Reguzzoni, A. Stella and F. Lévy, Phys. Rev. B: Condens. Matter Mater. Phys., 1986, 33, 2422-2428.

10 T. Yamasaki, N. Suzuki and K. Motizuki, J. Phys. C: Solid State Phys., 1987, 20, 395-404.

$11 \mathrm{~J} . \quad$ W. Lyding, M. T. Ratajack, C. R. Kannewurf, W. H. Goodman, J. A. Ibers and R. E. Marsh, J. Phys. Chem. Solids, 1982, 43, 599-607.

12 R. K. Sharma, G. Kedarnath, A. Wadawale, C. A. Betty, B. Vishwanadh and V. K. Jain, Dalton Trans., 2012, 41, 12129-12138.

13 M. A. Buhannic, P. Colombet, M. Danot and G. Calvarin, J. Solid State Chem., 1987, 69, 280-288.

14 Y. Arnaud, M. Chevreton, A. Ahouandjinou, M. Danot and J. Rouxel, J. Solid State Chem., 1976, 18, 9-15.

15 G. Calvarin, J. R. Gavarri, M. A. Buhannic, P. Colombet and M. Danot, Rev. Phys. Appl., 1987, 22, 1131-1138.

16 Y. Arnaud, M. Chevreton, A. Ahouandjinou, M. Danot and J. Rouxel, J. Solid State Chem., 1976, 18, 9-15.

17 D. R. Huntley, M. J. Sienko and K. Hiebl, J. Solid State Chem., 1984, 52, 233-243.

18 E. G. Shkvarina, A. N. Titov, S. G. Titova and O. M. Fedorova, J. Struct. Chem., 2016, 57, 710-716.

19 A. L. Hector, W. Levason, G. Reid, S. D. Reid and M. Webster, Chem. Mater., 2008, 20, 5100-5106.

20 B. L. Morris, R. H. Plovnick and A. Wold, Solid State Commun., 1969, 7, 291-293.

21 R. H. Plovnick, D. S. Perloff, M. Vlasse and A. Wold, J. Phys. Chem. Solids, 1968, 29, 1935-1940.

22 C. Sanchez-Perez, C. Knapp, M. M. Karjalainen, R. Oilunkaniemi, C. J. Carmalt and R. Laitinen, Dalton Trans., 2018, 47, 5415-5421.

23 C. E. Knapp and C. J. Carmalt, Chem. Soc. Rev., 2016, 45, 1036-1064. 
24 N. D. Boscher, C. J. Carmalt and I. P. Parkin, Chem. Vap. Deposition, 2006, 12, 54-58.

25 N. D. Boscher, C. J. Carmalt and I. P. Parkin, J. Mater. Chem., 2006, 16, 122-127.

26 R. G. Palgrave and I. P. Parkin, New J. Chem., 2006, 30, 505514.

27 E. S. Peters, C. J. Carmalt and I. P. Parkin, J. Mater. Chem., 2004, 14, 3474.

28 S. D. Reid, A. L. Hector, W. Levason, G. Reid, B. J. Waller and M. Webster, Dalton Trans., 2007, 4769-4777.

29 P. J. McKarns, T. S. Lewkebandara, G. P. A. Yap, L. M. LiableSands, A. L. Rheingold and C. H. Winter, Inorg. Chem., 1998, 37, 418-424.

30 A. C. Larson and R. B. Von Dreele, General Structure Analysis System, The University of California, Los Alamos, NM 87545, 1985.

31 C. Powell, A. Jablonski, I. Tilinin, S. Tanuma and D. Penn, J. Electron Spectrosc. Relat. Phenom., 1999, 98-99, 1-15.

32 R. J. Toh, Z. Sofer and M. Pumera, J. Mater. Chem. A, 2016, 4, 18322-18334.

33 A. S. Shkvarin, Y. M. Yarmoshenko, A. I. Merentsov, E. G. Shkvarina, E. A. Suslov, M. S. Brezhestovsky,
O. V. Bushkova and A. N. Titov, RSC Adv., 2016, 6, 106527106539.

34 M. C. Biesinger, L. W. M. Lau, A. R. Gerson and R. S. C. Smart, Appl. Surf. Sci., 2010, 257, 887-898.

35 M. Shenasa, S. Sainkar and D. Lichtman, J. Electron Spectrosc. Relat. Phenom., 1986, 40, 329-337.

36 Q. Zheng, X. Cheng and H. Li, Catalysts, 2015, 5, 1079-1091. 37 M. C. Biesinger, B. P. Payne, A. P. Grosvenor, L. W. M. Lau, A. R. Gerson and R. S. C. Smart, Appl. Surf. Sci., 2011, 257, 2717-2730.

38 S. L. Benjamin, C. H. (Kees) de Groot, C. Gurnani, A. L. Hector, R. Huang, K. Ignatyev, W. Levason, S. J. Pearce, F. Thomas and G. Reid, Chem. Mater., 2013, 25, 4719-4724.

39 P. Mulpur, T. M. Rattan and V. Kamisetti, J. Nanosci., 2013, 2013, 1-5.

40 K. Song, Y. Lee, M. R. Jo, K. M. Nam and Y.-M. Kang, Nanotechnology, 2012, 23, 505401.

$41 \mathrm{~K}$. Momma and F. Izumi, VESTA 3 for three-dimensional visualization of crystal, volumetric and morphology data, $J$. Appl. Crystallogr., 2011, 44, 1272-1276. 